\title{
Urgent aftershock observation of the 2004 off the Kii Peninsula earthquake using ocean bottom seismometers
}

\author{
Shin'ichi Sakai ${ }^{1}$, Tomoaki Yamada ${ }^{1}$, Masanao Shinohara ${ }^{1}$, Hiroko Hagiwara ${ }^{1}$, Toshihiko Kanazawa ${ }^{1}$, Koichiro Obana ${ }^{2}$, \\ Shuichi Kodaira ${ }^{2}$, and Yoshiyuki Kaneda ${ }^{2}$ \\ ${ }^{1}$ Earthquake Research Institute, University of Tokyo, 1-1-1 Yayoi, Bunkyo-ku, Tokyo 113-0032, Japan \\ ${ }^{2}$ Japan Agency for Marine-Earth Science and Technology, 2-15 Natsushima-cho, Yokosuka 237-0061, Japan
}

(Received February 18, 2005; Revised April 13, 2005; Accepted April 14, 2005)

\begin{abstract}
The 2004 off the Kii Peninsula earthquake occurred on September 5, 2004. Knowing the precise aftershock distribution is important for understanding the mechanism of this earthquake. However, the hypocenter of the main shock was located more than $100 \mathrm{~km}$ offshore from the nearest station of the land observation network. In the three days after the main shock, we started ocean bottom seismometer (OBS) observation in order to determine the precise distribution of the aftershocks. We assumed a seismic velocity structure for the hypocenter calculation, based on the results of previous seismic refraction study. The station corrections were incorporated to locate the hypocenter precisely. The hypocenters located within an area covered by five OBSs show relatively small errors. It is found that the OBS-located hypocenters are located about $5.5 \mathrm{~km}$ east-southeast from those by JMA and the depth range of the aftershocks is about 5-25 km just beneath the Nankai trough axis. The aftershock hypocenters can be grouped into two clusters at different depths of about $10 \mathrm{~km}$ and about $20 \mathrm{~km}$. It is inferred that the main shock also has a depth of 5-25 km. Since this extent of the main shock was larger than one of the oceanic crust of the Philippine Sea plate, the fault plane of the main shock extended at the upper most mantle of the Philippine Sea plate. Although we cannot assign the actual fault plane of the main shock form our observation results, it is clarified that intra-plate earthquakes occurred near the trench region. Our OBS result supports that the main shock was the earthquake not at the plate boundary but within the bending Philippine Sea plate near the trough axis.
\end{abstract}

Key words: The 2004 off the Kii Peninsula earthquake, aftershock, ocean bottom seismometer (OBS), intraplate, Philippine Sea plate, Tonankai earthquake, Nankai trough.

\section{Introduction}

An earthquake with a local body wave magnitude $\left(\mathrm{M}_{\mathrm{JMA}}\right)$ of 7.4 occurred near the Nankai trough axis, approximately 100-150 km offshore from the Kii peninsula, Japan, at 14:57, September 5, 2004 (UT). This earthquake was named the 2004 off the Kii Peninsula earthquake by the Japan Metrological Agency (JMA). An earthquake of M7.1 had occurred about $30 \mathrm{~km}$ west of the main shock epicenter about five hours before the main shock. Among aftershocks followed the main shock, the largest event was that with the magnitude $M=6.5$ at 14:58, on September 8, 2004 (UT). The maximum height of tsunami accompanied with the main shock was about $0.9 \mathrm{~m}$ at Kushimoto (Satake et al., 2005). Fortunately, there was no report of damage to residential areas and to people either.

The Nankai trough, where this earthquake occurred nearby, is one of the active convergent plate boundaries where great historic earthquakes have been repeated. On the basis of previous geodetic and seismological studies, there are remarkable regularities in the space-time distribution of great earthquakes along the Nankai trough (e.g., Ando,

Copy right(c) The Society of Geomagnetism and Earth, Planetary and Space Sciences (SGEPSS); The Seismological Society of Japan; The Volcanological Society of Japan; The Geodetic Society of Japan; The Japanese Society for Planetary Sciences; TERRAPUB.
1975). Ando (1975) showed that the recurrence interval of the great earthquakes is approximately 100-200 years. The last great earthquakes along the Nankai trough were in 1944 (Tonankai earthquake, Ms=8.16) and 1946 (Nankai earthquake, Ms=8.19); both hypocenters were located off the Kii Peninsula at the approximate depth of $30 \mathrm{~km}$, with a large uncertainty from a depth of 0 to $40 \mathrm{~km}$ (Kanamori, 1972). Both of the M8 class events were interpreted as low angle thrust faulting at the plate boundary interface with the relative movement of the northwestward underthrusting of the Philippine Sea plate against the overriding southwestern Japan (Kanamori, 1972; Ando, 1975). This 2004 off the Kii Peninsula earthquake is located at seaward border of the coseismic rupture zone of the 1944 Tonankai earthquake (e.g. Kikuchi et al., 2003). The fault plane solution of the 2004 off the Kii Peninsula earthquake is estimated to be a high-angle thrust-type with the N-S striking $P$-axis, indicating that this event was not an inter-plate but intra-plate one (e.g. Ito et al., 2005).

In order to determine the actual fault plane of the 2004 Kii Peninsula earthquake, we must retrieve the precise aftershock distribution. Information of the precise aftershock distribution provides important constants on the main shock generation mechanisms. In addition, we can utilize this information for studies of the source process and the crustal 


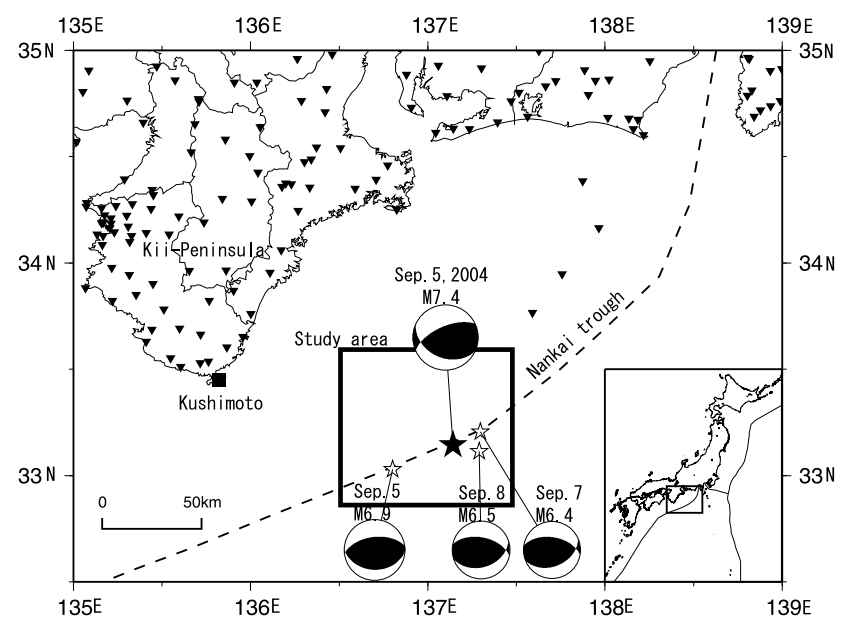

Fig. 1. Location map of the 2004 off the Kii Peninsula earthquake. Our study area is indicated by a rectangle near the axis of the Nankai trough. Solid star and open stars indicate the main shock and the aftershocks larger than M6.0, respectively. The focal mechanism solutions obtained by the first motions are shown using lower hemisphere projection. Inverted smaller triangles indicate the telemetered seismic stations, located more than $100 \mathrm{~km}$ far from the earthquakes concerned. Broken line indicates the Nankai Trough axis which is a plate boundary between the Philippine Sea plate and the overriding Eurasian plate.

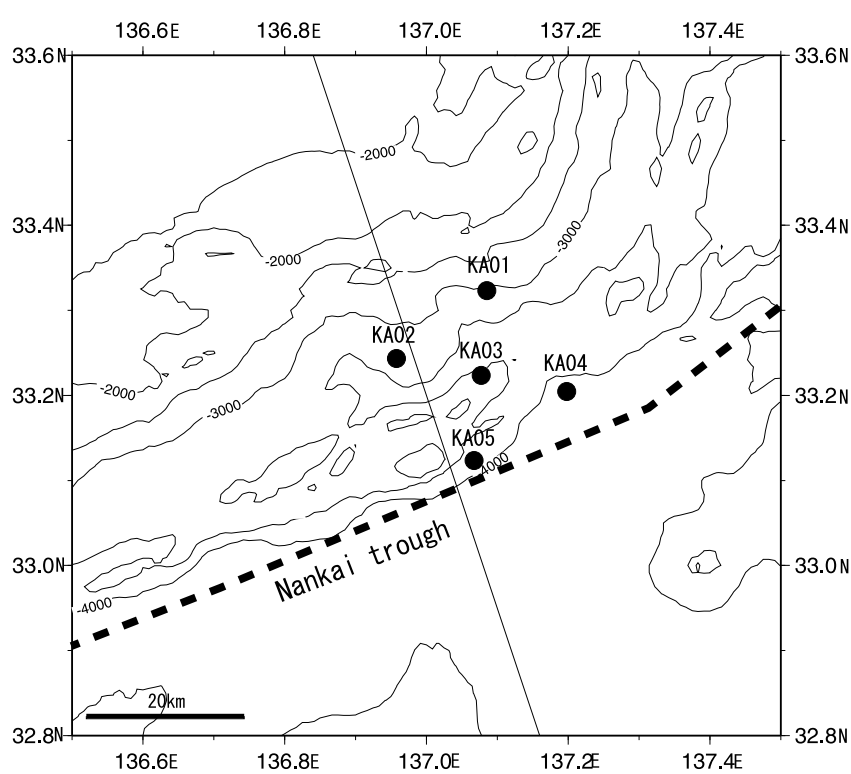

Fig. 2. Location map of the OBSs with bathymetric feature. Circles indicate the five OBSs deployed on September 8. Broken line indicates the Nankai Trough axis. The water depths of OBSs range from 3000 $\mathrm{m}$ to $4200 \mathrm{~m}$. An NNW-SSE striking solid line indicates the profile of the seismic survey using pop-up type OBSs in 1998 (Nakanishi et al., 2002).

movement associated with the main shock. Information of the focal process of the 2004 off the Kii Peninsula earthquake is also necessary to study its influence on the next Tonankai Earthquake with M8. It is, however, difficult to locate precisely the aftershocks using data from the land seismic network alone, because the epicenters are located $100 \mathrm{~km}$ or more away from the observation station.

We carried out a seismic observation with ocean bottom seismometers (OBSs) to locate the aftershocks precisely. The OBS observation is useful to retrieve the seis-

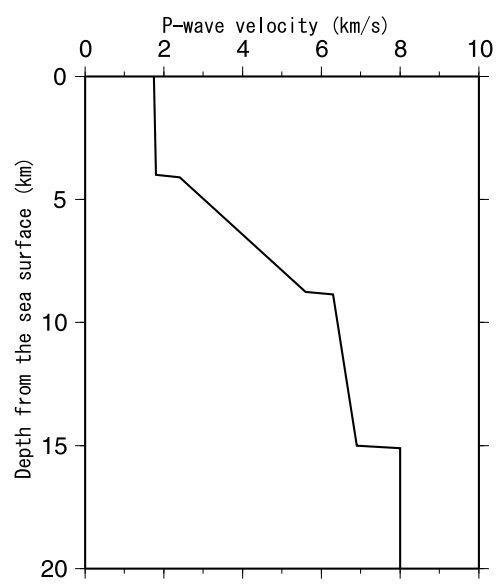

Fig. 3. $P$-wave velocity structure model used for the hypocenter determination. Vertical axis shows the depth from the sea surface. The model is derived from the refraction experiments carried out using the pop-up type OBSs in 1998 (Nakanishi et al., 2002). $S$-wave velocities were introduced from that the ratio of the $P$-wave and the $S$-wave velocities is 1.73 , except the surface layer of the ratio was 4.00 . The assumed moho-depth is $15 \mathrm{~km}$.

Table 1. OBS location parameters and station corrections for $P$ - and $S$-waves used in the hypocenter determination.

\begin{tabular}{rrrrrr}
\hline Station & Latitude & Longitude & Elevation & \multicolumn{2}{c}{ Station-correction } \\
\hline & degree $(\mathrm{N})$ & degree $(\mathrm{E})$ & $\mathrm{m}$ & $\mathrm{P}$-wave(s) & S-wave(s) \\
\hline KA01 & 33.32444 & 137.08334 & -3030 & 0.03 & -1.06 \\
KA02 & 33.24222 & 136.95543 & -3276 & -0.19 & -1.57 \\
KA03 & 33.22491 & 137.07520 & -3385 & -0.30 & -1.88 \\
KA04 & 33.20438 & 137.19488 & -4285 & -0.37 & -1.82 \\
KA05 & 33.12185 & 137.06547 & -3785 & -0.25 & -1.64 \\
\hline
\end{tabular}

micity with high resolution in marine areas. For example, Shinohara et al. (2004) identified aftershocks of the 2003 Tokachi-oki earthquake (M8.2) using the OBS observation. In this paper, we describe our OBS observation and discuss the tectonic implications of the aftershock distributions located with the OBSs.

\section{Seismic Observation}

In order to retrieve the precise distribution of the aftershock activity of the 2004 off the Kii Peninsula earthquake as quickly as possible, we started to deploy the OBSs on the source region three days after the main shock using a helicopter chartered by Earthquake Research Institute (Fig. 2). The OBS network did not cover the whole region of the aftershocks but only the area close to the main shock epicenter, because the helicopter was able to carry only five pop-up type OBSs. Since the main shock epicenter was located far from the land station network, it was inferred that the depth of the main shock was shallower than the depth determined by JMA, about $44 \mathrm{~km}$. The OBS spacing was approximately $10 \mathrm{~km}$, which allowed the precise hypocenter determination of the aftershocks. We used the digital recording OBS systems, which have vertical and horizontal velocity-sensitive electro-magnetic geophones with the natural frequency of $4.5 \mathrm{~Hz}$. The crystal oscillator, installed within the OBSs, provided accurate timing better than 0.05 $\mathrm{s}$ for the whole observation period.

From September 13 to 14, 2004, twenty-five OBSs were deployed newly by the R/V Kaiyo belonging to the Japan 
(a)

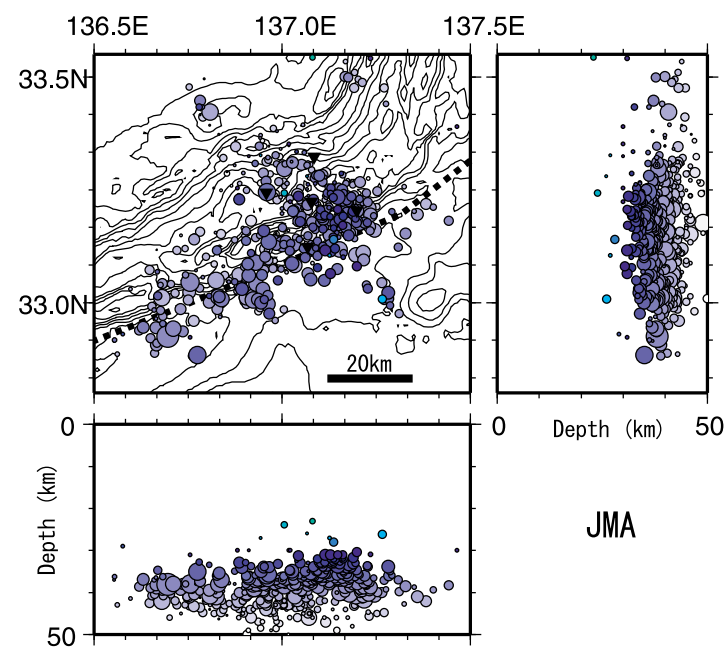

(b)

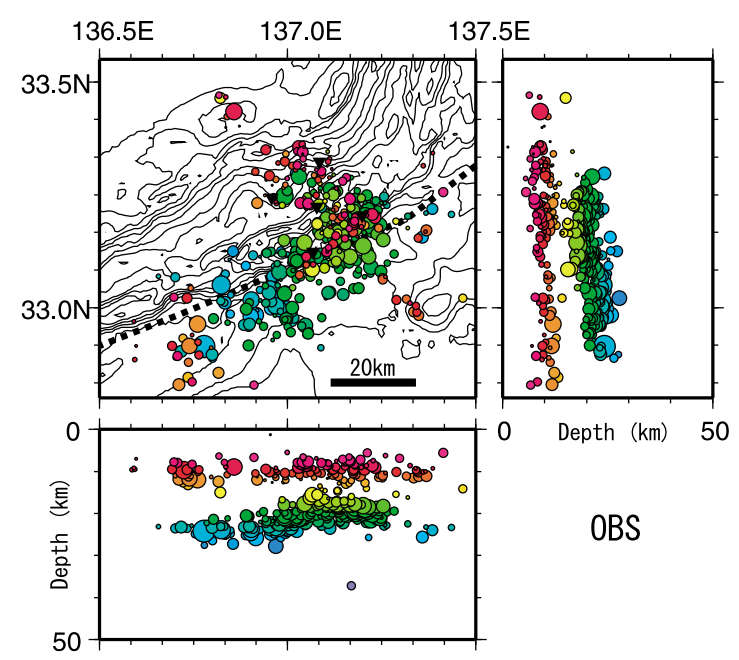

Fig. 4. Comparison between (a) the hypocenters determined by JMA and (b) those determined in this study. Vertical sections along latitude (right) and longitude (lower) are also shown, respectively. Inverted triangles and the broken line indicate the positions of the five OBSs and the Nankai trough axis, respectively. Hypocenters which located within the area covered by the OBSs have small spatial errors less than $1 \mathrm{~km}$ in the horizontal direction and less than $3 \mathrm{~km}$ in depth. Focal depth of the earthquakes is indicated by color, blue corresponds to deeper and red corresponds to shallower. Most of the JMA-located hypocenters are deeper than $30 \mathrm{~km}$, and most of the OBS-located hypocenters are shallower than $30 \mathrm{~km}$. The shallower group of the OBS-located hypocenters is concentrated mainly at 5-15 km depth in the approximate NW-SE direction, perpendicular to the trough axis. The deeper hypocenters are mostly distributed at $15-25 \mathrm{~km}$ depth in the approximate NE-SW direction, parallel to the trough axis.

Agency for Marine-Earth Science and Technology Center (JAMSTEC) in cooperation with the ERI, University of Tokyo, Hokkaido University, Tohoku University and Kyushu University. During this cruise, five OBSs were recovered after the determination of the OBS locations on the sea bottom using the acoustic ranging system. The accuracy of the acoustic ranging is estimated to be better than ten meters. Later, these twenty-five OBSs were recovered from October 12 to 13,2004 . In this study, we used waveform data from the first five OBSs. In the future, the more detailed aftershock distribution in the wider observation area than that of the first five OBSs will be studied.

\section{Hypocenter Distribution}

We extracted event data using JMA's hypocenter list from the continuous digital records of the five OBSs. The $P$ and $S$ wave arrival times were identified manually using a computer-aided processing system (Urabe and Tsukada, 1991). An extensive seismic experiment was carried out near the main shock area using controlled seismic sources and the OBSs, in order to obtain the detailed seismic structure in 1998 (Nakanishi et al., 2002). Although the seismic velocity structure around the aftershock area of the 2004 Kii-Peninsula earthquake has large lateral heterogeneity in its seismic structure due to the plate subduction and a thick non-uniform sedimentary layer, we assumed a simple onedimensional seismic velocity structure based on the results of the refraction study of Nakanishi et al. (2002) for the hypocenter calculation (Fig. 3). To improve the hypocenter solutions, we incorporated station corrections for $P$ - and $S$-wave arrivals. The station corrections partly reflect the thickness of the sedimentary layers beneath the OBS sites.

The hypocenters were determined using the maximumlikelihood estimation technique of Hirata and Matsu'ura (1987). Since the $S$-wave velocity structure was not ob- tained by Nakanishi et al. (2002), we determined the $S$ wave velocity of the sedimentary layer using the waveform data just below station OBS10 in Nakanishi et al. (2002). We assumed that the ratio of $P$ - to $S$-wave velocity for the sedimentary layer was 4.00 and that the ratio for the other layers was 1.73. For each OBS site, we read the arrival time of the $S p$ converted wave, which is a $P$-wave converted from an $S$-wave at the acoustic basement. The difference between the $S p$ - and the $P$-wave arrival times was estimated. The initial values of the station-correction for $P$ - and $S$-waves at each OBS site were estimated from the one-dimensional model of $P$ - and $S$-wave velocities and the Sp- $P$ time.

Next, we calculated the temporal hypocenter using the initial data set of the station-corrections. The averaged differences between the observed travel times and the estimated travel times (O-C times) were calculated for each OBS. After adding the averaged O-C times to the previous station-correction values, we relocated the hypocenters again. New averaged O-C times for each station were calculated from the results of the second location procedure. Adding the new averaged $\mathrm{O}-\mathrm{C}$ times to the previous correction values, we relocated the hypocenters again. This relocation process was repeated five times at maximum. Then, the final O-C times for each OBS site decrease, resulting in less than $0.01 \mathrm{~s}$. The final station-correction values obtained for each OBS site are listed in Table 1. During this analysis, the RMS of the O-C times for each hypocenter determination improved from $0.075 \mathrm{~s}$ to $0.030 \mathrm{~s}$ for $P$-wave arrival and from 0.272 s to 0.116 s for $S$-wave arrival. The shape of the frequency curve for the O-C times became sharp, and the deviation reduced.

Among 765 events, which were draw from the event list by JMA, 685 events could be located using more than three $P$-wave readings and one $S$-wave reading. Since some 


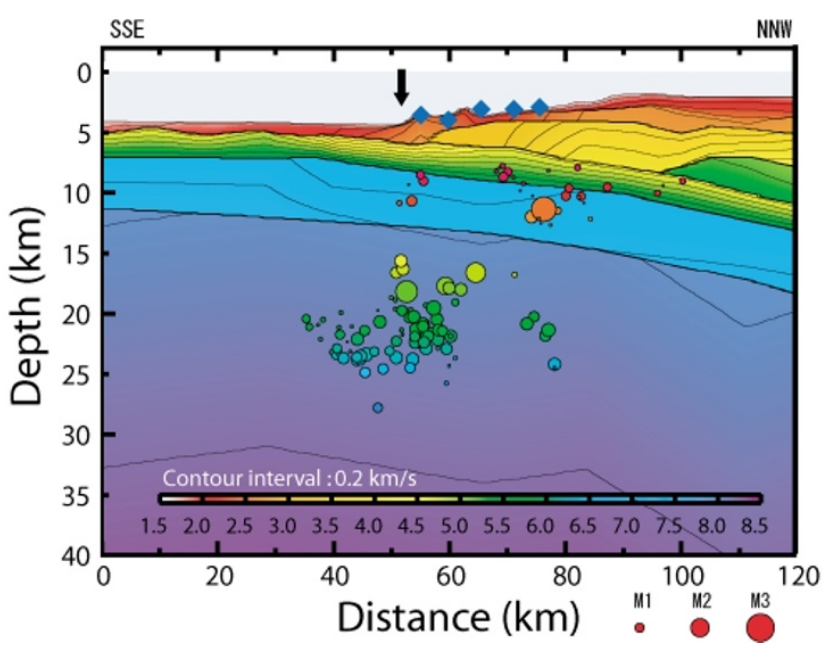

Fig. 5. NNW-SSE striking vertical cross-section view of the OBS-located hypocenters along a line shown in Fig. 2 . The $P$-wave velocity structure shown in this figure is taken from Nakanishi et al. (2002). Arrow and the blue diamonds indicate the axis of the Nankai trough and our OBSs. Among the hypocenter with small spatial errors, we selected the hypocenters within $8 \mathrm{~km}$ of the distance from the profile plane. The shallower group is located within the oceanic crust of the subducting Philippine Sea plate. The deeper group is located within the upper mantle of the subducting Philippine Sea plate. There are few hypocenters on the plate boundary or within the accretionary prism.

hypocenters occurred far from the OBS network, these solutions were not solved correctly on the hypocenter determination program. Finally, we could determine 480 hypocenters of the 685 events corresponding to those determined by JMA from the land seismic stations. The magnitude of JMA catalogue was defined as the magnitude of OBSlocated hypocenters.

It is found that the OBS-located hypocenters shift about $5.5 \mathrm{~km}$ east-southeast on the average from those by JMA (Fig. 4). Most of the JMA-located hypocenters are deeper than $30 \mathrm{~km}$, whereas most of the OBS-located hypocenters are shallower than $30 \mathrm{~km}$. The hypocenters determined by the OBSs can be classified into two different depth groups: the shallower group of the hypocenters is concentrated mainly at $5-15 \mathrm{~km}$ depth in the approximate NW-SE direction, nearly perpendicular to the trough axis; the deeper hypocenters are mostly distributed at $15-25 \mathrm{~km}$ depth in the approximate NE-SW direction, nearly parallel to the trough axis.

\section{Discussion}

Among the OBS-located 480 hypocenters, 365 hypocenters have small spatial errors of less than $1 \mathrm{~km}$ in the horizontal direction and less than $3 \mathrm{~km}$ in depth. The epicenters of these hypocenters are confined within the network of five OBSs. The well-located hypocenters have the depth of about 5-25 km and they are divided into two groups in terms of depth. In a cross-section of the hypocentral distribution projected on a vertical profile of the seismic velocity along the NNW-SSE striking survey line (shown in Fig. 2) of Nakanishi et al. (2002), the relation between the aftershock distribution and the velocity structure can be clarified (Fig. 5). The shallower group is located within the oceanic crust of the bending and subducting Philippine Sea plate. There are few hypocenters on the plate boundary and within the accretionary prism. The deeper group is located within the upper mantle of the subducting slab. We cannot recognize any clear dipping plane formed by the hypocenters in the projected distribution (Fig. 5). Thus, most OBS-located events were intra-plate earthquakes within the down going Philippine Sea plate.

There is a distinct difference between September 8 and 9 in 2004 (JST), in the epicenter distribution (Fig. 6). The aftershocks on eighth were concentrated around the main shock. The aftershocks on ninth, however, were rather located on the broad area. The largest aftershock with M6.5 occurred at about $10 \mathrm{~km}$ southeast from the main shock at 23:58, on September 8, 2004 (JST). The stress state might be changed by the largest aftershock.

Next, we investigate the aftershock distribution before and after the event of M6.5 on September 8. In general, the OBS close to the epicenter of the aftershocks with relatively large magnitude cannot record the total wave trains around the $S$-wave, because of the limited dynamic range of the OBS recording system. In these cases, the $S$-wave arrival time is not assigned. Thus, we cannot determine the hypocenters of the relatively large aftershocks with the small special errors. Therefore, the number of reliable

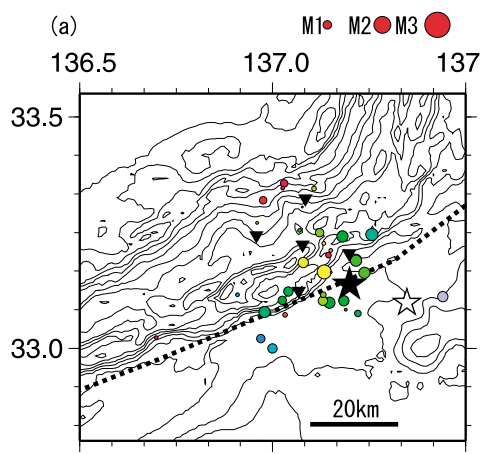

Sep. 8, 17:00-23:59, 2004 (JST) Sep. 8, 08:00-14:59, 2004 (UT)

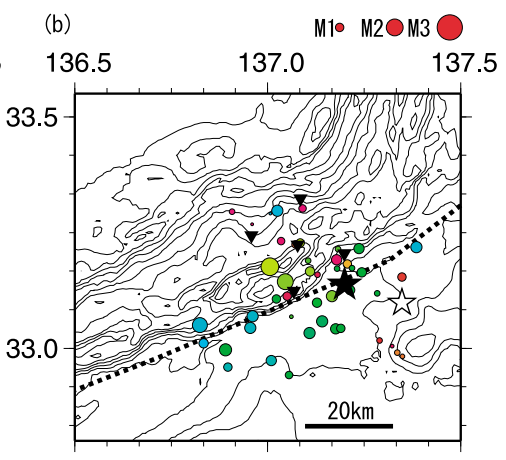

Sep. 9, 00:00-23:59, 2004 (JST) Sep. 8, 15:00-Sep. 9, 14:59, 2004 (UT)

Fig. 6. Distribution of the aftershocks on (a) Sep. 8 and (b) Sep. 9, 2004 (JST). Inverted triangles and the broken line indicate the positions of the OBSs and the Nankai trough axis, respectively. Solid star and the open star indicate the epicenter of the main shock and the largest aftershock. Focal depth of the aftershocks is color coded, blue corresponds to deeper and red corresponds to shallower. 
(a)
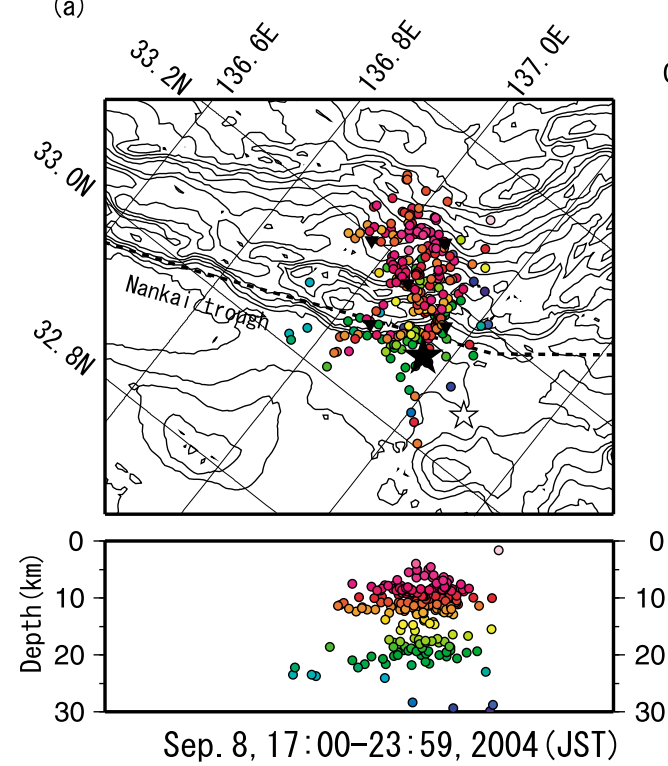

Sep. 8, 08:00-14:59, 2004 (UT) (b)
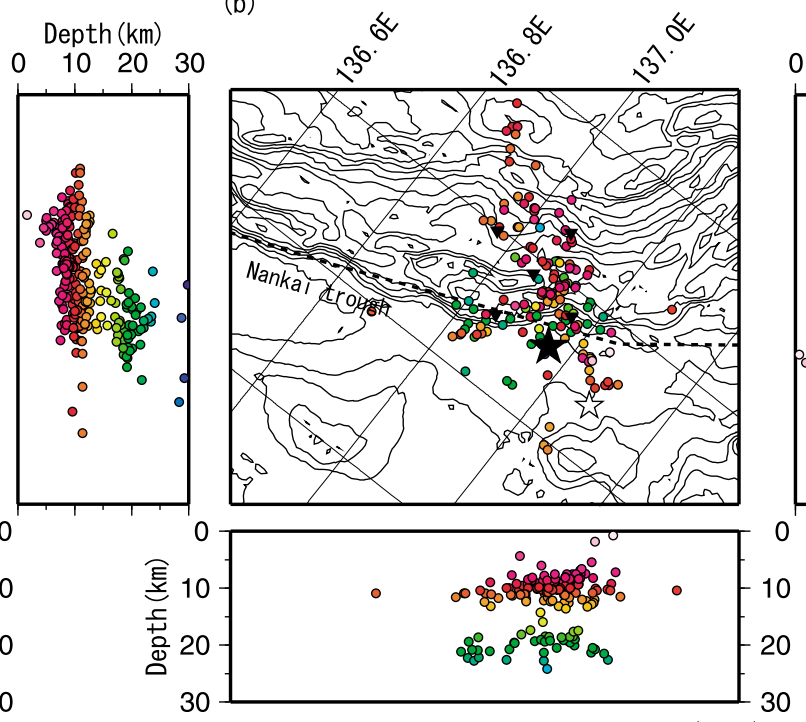

Sep. 9, 00:00-06:59, 2004 (JST)

Sep. 8, 15:00-21:59, 2004 (UT)

Fig. 7. Distribution of the aftershocks for seven hours duration (a) before and (b) after the occurrence of the largest aftershock at 23:58 on Sep. 8, 2004 (JST). The top and bottom lines of the epicentral map are converted to the strike of the fault mechanism of the main shock. Inverted triangles and the broken line indicate the positions of the OBSs and the Nankai trough axis. Solid star and the open star indicate the epicenter of the main shock and the largest aftershock. Focal depth of the aftershocks is color coded, blue corresponds to deeper and red corresponds to shallower. Vertical cross-sections are also shown. There were few aftershocks in the region between the two separate depth groups after the largest aftershock. (Fig. 7(b)).

hypocenters is decreased. In the case of smaller earthquake, we can read the arrival time of $S$-wave using our OBS data, because the waveform amplitude is within the OBS dynamic range. For this reason, we could detect even the smaller earthquake in a special care, and the number of reliable hypocenters was increased. Here, we analyze, in detail, the data observed over seven hours both before and after the largest aftershock of M6.5 (Fig. 7). Two hundred seventytwo hypocenters were determined for the seven hours before the largest aftershock occurrence, and 151 hypocenters were located for the next seven hours after the largest aftershock. Hypocentral errors for both of the 272 and 151 aftershocks were less than $1 \mathrm{~km}$ in the horizontal direction and less than $3 \mathrm{~km}$ in the vertical direction. Figure 7(a) shows some seismic activities in an area between the two separated depth groups of high seismicity. The general trend of the aftershocks shown in Fig. 7(a) seems to incline toward the south. This southward inclined pattern of the aftershocks may correlate with the rupture plane during the main shock or the larger aftershock, although the pattern is not dominant. There were few aftershocks in the region between the two separate depth groups after the largest aftershock. (Fig. 7(b)).

The largest aftershock was relocated using the OBS data in the shallow depth group, about $7 \mathrm{~km}$. Since the amplitude of the observed waveform was too large and saturated, the arrival time of the $S$-wave was difficult to detect. In addition, the epicenter of the largest aftershock was located outside of the OBS network. Therefore, the determined depth of the largest aftershock has a large error. The aftershocks of the shallow depth group expanded to the northwest and southeast to some extent after the largest aftershock occurrence. There was, however, no clear change in the af- tershock distribution of the deeper group. Although the largest aftershock has the same thrust-type of focal mechanism with the $P$-axis in the northwest-southeast direction as the main shock, the distribution of the OBS-located aftershocks after the largest aftershock dose not suggest any dipping plane associated with the fault plane of the event with M6.5. We suggest that one of the possible reasons of no dipping plane in Fig. 7 is due to limited spatial coverage of the OBS network.

In the future study based on the additional 25 OBSs, we would like to relocate the aftershocks to reveal more detailed characteristics about the seismic activities associated the 2004 off the Kii Peninsula earthquake.

Considering that the accumulated strains around plate boundary are mainly released by intermittent underthrusting type earthquakes at the plate boundary interface, we are likely to think any larger earthquake, near the areas on the landward side of the trough axis to be those of inter-plate earthquake with the low-angle fault plane solution. We must, however, recognize that the possibility of the other type events such as those of intra-plate earthquakes. To make clear whether such intra-plate earthquakes are rare or normal, we should investigate the past larger intra-plate earthquakes occurred within the Philippine Sea plate around the region southward of the Kii Peninsula.

\section{Conclusion}

In order to obtain the precise aftershock distribution of the 2004 off the Kii Peninsula earthquake, we carried a seismic observation using five pop-up type OBSs from September 8 to 14, 2004. For the hypocenter calculation, we assumed a simple one-dimensional seismic velocity structure based on the result of the previous seismic refraction study, 
although the aftershock area has large lateral heterogeneity in seismic velocity structure due to plate subduction and the thick non-uniform sedimentary layer. In order to improve the hypocenter calculation, station corrections for $P$ - and $S$-wave arrivals were introduced. The hypocenters which were located within the area covered by the five OBSs have small spatial errors less than $1 \mathrm{~km}$ in the horizontal direction and less than $3 \mathrm{~km}$ in depth. The aftershocks were located at depths of about 5-25 km, mainly concentrated at two different depths of 5-15 km and 15-25 km. This suggests that the main shock was at a depth of 5-25 km. The distribution of the OBS-located aftershocks did not coincide with the thrust type focal mechanisms of the main shock and the largest aftershock. There was some difference between the distribution of aftershocks just before and just after the largest aftershock, which occurred on September 8. The aftershocks before the largest aftershock were concentrated around the main shock.

We located aftershocks precisely, using our individual OBS observation data. Although the OBS-located hypocenters are not sufficient to assign the actual fault planes of the main shock and the larger aftershocks, we can recognize a southward inclined pattern of the hypocenters, especially those on September 8, 2004.

Acknowledgments. We thank Dr. T. Eguchi and Dr. J. Pulliam for many comments on the manuscript. We would like to thank the pilot and crew members of the helicopter for deployment of the OBSs, the captain and crew members of the R/V Kaiyo (Japan Marine Science and Technology Center) for recovering the OBSs. Dr. Kinoshita, chief scientist of the KY04-01, kindly provided the operation time for OBSs. We also thank Mr. Hashimoto, Mr. Inoue and Mr. Yagi for their preparation of the OBS observation. Most of the figures were created using GMT (Wessel and Smith, 1995). This work is a part of the Research on the Tonankai and Nankai earthquakes funded by the Ministry of Education, Culture, Sports,
Science, and Technology.

\section{References}

Ando, M., Source mechanisms and tectonic significance of historical earthquakes along the Nankai Trough, Japan, Tectonophysics, 27, 119-140, 1975.

Hirata, N. and M. Matsu'ura, Maximum-likelihood estimation of hypocenter with origin time eliminated using nonlinear inversion technique, Phys. Earth Planet. Inter., 47, 50-61, 1987.

Ito, Y., T. Matsumoto, H. Kimura, H. Matsubayashi, K. Obara, and S. Sekiguchi, Spatial distribution of centroid moment tensor solutions for the 2004 off Kii peninsula earthquakes, Earth Planets Space, 57, 351356, 2005.

Kanamori, H., Tectonic implications of the 1944 Tonankai and the 1946 Nankaido earthquakes, Phys. Earth Planet. Inter., 5, 129-139, 1972.

Kikuchi, M., M. Nakamura, and K. Yoshioka, Source rupture processes of the 1944 Tonankai earthquake and the 1945 Mikawa earthquake derived from low-gain seismograms, Earth Planets Space, 55, 159-172, 2003.

Nakanishi, A., N. Takahashi, J. O. Park, S. Miura, S. Kodaira, Y. Kaneda, N. Hirata, T. Iwasaki, and M. Nakamura, Crustal structure across the coseismic rupture zone of the 1944 Tonankai earthquake, the central Nankai Trough seismogenic zone, J. Geophys. Res., 107, 2002.

Satake, K., T. Baba, K. Hirata, S. Iwasaki, T. Kato, S. Koshimura, J. Takenaka, and Y. Terada, Tsunami source of the 2004 off the Kii peninsula earthquakes inferred from offshore tsunami and coastal tide gauges, Earth Planets Space, 57, 173-178, 2005.

Shinohara, M., T. Yamada, T. Kanazawa, N. Hirata, Y. Kaneda, T. Takanami, H. Mikada, K. Suehiro, S. Sakai, T. Watanabe, K. Uehira, Y. Murai, N. Takahashi, M. Nishino, K. Mochizuki, T. Sato, E. Araki, R. Hino, K. Uhira, H. Shiobara, and H. Shimizu, Aftershock observation of the 2003 Tokachi-oki earthquake by using dense ocean bottom seismometer network, Earth Planets Space, 56, 295-300, 2004.

Urabe, T. and S. Tsukada, A workstation-assisted processing system for waveform data from microearthquake networks, Abstracts of Spring Meeting of Seismological Society of Japan, 70, 1991 (in Japanese).

Wessel, P. and W. H. F. Smith, New version of the generic mapping tools released, Eos Trans. AGU, 76, 329, 1995.

S. Sakai (e-mail: coco@eri.u-tokyo.ac.jp), T. Yamada, M. Shinohara, H. Hagiwara, T. Kanazawa, K. Obana, S. Kodaira, and Y. Kaneda 